\title{
Fire Resistance of Steel Connectors of Precast Lightweight Concrete Walls
}

Jen-Hao Chi

epartment of Fire Science, WuFeng University, Chiayi County, Taiwan, R.O.C., jackchi@wfu.edu.tw

Maochieh Chi

Department of Fire Science, WuFeng University, Chiayi County, Taiwan, R.O.C.

Yue-Lin Huang

Department of Civil Engineering, National Chung Hsing University, Taichung, Taiwan, R.O.C.

Follow this and additional works at: https://jmstt.ntou.edu.tw/journal

Part of the Fresh Water Studies Commons, Marine Biology Commons, Ocean Engineering Commons, Oceanography Commons, and the Other Oceanography and Atmospheric Sciences and Meteorology Commons

\section{Recommended Citation}

Chi, Jen-Hao; Chi, Maochieh; and Huang, Yue-Lin (2021) "Fire Resistance of Steel Connectors of Precast Lightweight Concrete Walls," Journal of Marine Science and Technology. Vol. 29: Iss. 4, Article 4.

DOI: 10.51400/2709-6998.1584

Available at: https://jmstt.ntou.edu.tw/journal/vol29/iss4/4

This Research Article is brought to you for free and open access by Journal of Marine Science and Technology. It has been accepted for inclusion in Journal of Marine Science and Technology by an authorized editor of Journal of Marine Science and Technology. 
Fire Resistance of Steel Connectors of Precast Lightweight Concrete Walls

\author{
Jen-Hao Chi ${ }^{a}$, Maochieh Chi ${ }^{a, *}$, Yue-Lin Huang ${ }^{b}$ \\ ${ }^{\text {a }}$ Department of Fire Science, WuFeng University, Chiayi County, Taiwan, ROC \\ ${ }^{\mathrm{b}}$ Department of Civil Engineering, National Chung Hsing University, Taichung, Taiwan, ROC
}

\begin{abstract}
In this study the fire test was performed to investigate the mechanic behaviors and failure patterns of precast normal weight concrete (NWC) and lightweight concrete (LWC) walls with three types of commonly used steel connectors, namely dry (61), wet (81), and bearing (56E) connectors. For the LWC wall specimens, on lateral application of tension, the cracking load values of the dry, wet, and bearing-type connectors were $95.1 \%, 86.3 \%$, and $83.0 \%$, respectively, of the original loads, and their ultimate load values were $81.6 \%, 90.7 \%$, and $85.0 \%$, respectively, of the original. In the shearing test after the fire resistance test, the cracking load value of the bearing-type connector was $88.2 \%$ of the original load. Moreover, all specimens exhibited a considerable loss in the ductility ratio after the fire resistance test. However, the hysteresis energy that can be absorbed and the seismic resistance of the LWC wall were superior to those of the NWC wall. Therefore, although the LWC and NWC walls exhibited similar failure patterns, steel connectors exhibited superior fire resistance for precast LWC walls.
\end{abstract}

Keywords: Steel connectors, Precast lightweight concrete wall, Failure patterns, Fire resistance

\section{Introduction}

$\mathrm{P}$ recast concrete is used in construction projects to ensure high construction quality and to reduce the construction time. Precast concrete increases the construction speed, improves engineering quality, reduces the construction period, and to a certain extent ameliorates the problem of labor shortage. Standardized and automated production of precast concrete benefits the environment and improves engineering quality [1].

Structural precast lightweight aggregate (LWA) concrete (LWAC) is generally used in marine environments for constructing long-span bridges, breakwaters, oil and gas platforms, and offshore structures, such as floating docks, decks, and railings along the waterfront. Precast lightweight concrete (LWC) counteracts the buoyant forces of water better than normal or heavy weight concrete.
Furthermore, precast LWC exhibits relatively low unit weight, superior thermal insulation characteristics, and enhanced durability, which contribute to a long service life of concrete structures [2]. In the United States, numerous material and design innovations have been achieved in constructing floating pier infrastructure with precast concrete technology [3]. Kim et al. [4] revealed that double walls made of precast concrete exhibit high integrity, and in their construction, enhanced quality is evident and relatively few delays occur. Furthermore, LWAC has been widely used in ship building because of its low density.

Fires are the most frequent disasters. Fires cause structural damage and render buildings unstable [5-8]. Most buildings in Taiwan are constructed of reinforced concrete. Although these concrete structures exhibit decent fire resistance, high-temperature fires may degrade concrete strength, which 
may endanger the structural integrity of buildings [9-12]. LWAC consists of LWA inside LWC sintered at a high temperature, which results in more pores inside the aggregate. This process results in superior thermal stability and low thermal conductivity as well as a low coefficient of thermal expansion [13-21].

The fire test was performed to study the fire resistance and mechanical properties of LWC and normal weight concrete (NWC) walls. The results revealed that after the fire test, the LWC wall exhibited cracking, yield, and ultimate strengths of $93.6 \%, 94.1 \%$, and $95.8 \%$, respectively. Furthermore, the stiffness and ductility of the wall were $85.4 \%$ and $99.6 \%$, respectively. By contrast, the cracking, yield, and ultimate strengths of the specimen after the fire test decreased to $76.3 \%, 78.3 \%$, and $72.5 \%$, respectively. Furthermore, the stiffness and ductility decreased to $74.8 \%$, and $81.0 \%$, respectively. Therefore, the fire resistance performance of LWAC components is superior to normal weight aggregate concrete (NWAC) [22]. In the fire resistance test, the failure patterns of the LWC wall specimens were similar to those of the NWC wall specimens. Although a clear downward trend was observed for the stiffness of the heavy wall and the change of the hysteresis energy after the fire test, the stiffness and hysteresis energy changes of the LWC wall after the test did not differ considerably from those before the fire resistance test. Thus, the hysteresis energy and seismic resistance of LWC walls are superior to those of NWC walls [23,24]. Furthermore, the use of LWAC in construction can reduce the weight of each concrete component and consequently reduce the lifting and transportation costs [25].

Steel connectors are typically used during the construction and installation of precast concrete walls. The connecting function of the steel connectors can be categorized into structural functions (suspension, support, fixation, sliding, and rotation), physical properties (wind pressure resistance and interlayer displacement absorption), construction requirements (construction facilities, interlayer displacement), and three other parts [25]. The connectors of precast concrete walls are critical components of the joint between the wall and the building's structure [25]. Therefore, in this study, three types of commonly used connectors, namely dry (61), wet (81), and bearing (56E) connectors, were placed in LWC and NWC wall specimens. The mechanic behaviors and failure patterns of the test specimens before and after the fire test were compared to understand the applicability of the three connectors commonly used in LWC walls.
The LWA used in this study was obtained from expanded clay from reservoir sludge. After hightemperature sintering, the aggregate appears reddish-brown or black and spherical in shape. The unit weight, particle density, porosity, and water absorption of the aggregate are $0.3-0.9 \mathrm{~g} / \mathrm{cm}^{3}$, $0.6-0.8 \mathrm{~g} / \mathrm{cm}^{3}, 70 \%$, and $8 \%-20 \%$, respectively. Because of the low density and multiporous properties, LWA is applied in building structures to reduce the weight and cross-sectional area of the structures and achieve the optimum use of space [26-30]. LWAC has been applied in housing structures and bridge structures in several countries. For example, LWAC was extensively used in the construction of the 42-story Prudential Life Building in Chicago and the 50-floor Australia Square Tower. Since 1954, LWA has been used for constructing buildings and bridge structures in the United Kingdom [31]. Since 1989, LWAC with a strength of up to $75 \mathrm{MPa}$ has been used for constructing large bridges in Norway [32]. Overall, LWAC outperforms NWAC. LWA produced using reservoir sludge can address the problems of resource scarcity and environmental concerns simultaneously $[23,24]$.

\section{Experimental program}

\subsection{Materials and mix design}

In this study, type I ordinary Portland cement manufactured according to the ASTM C 150 standard ("ASTM C 150. Standard Specification for Portland Cement. American Society for Testing and Materials," 2017 [33]) was obtained from Taiwan Cement Co., Ltd. and used as the main binder material. Coarse aggregates of sizes $4.76-9.52 \mathrm{~mm}$ and 9.52-12.7 $\mathrm{mm}$ were prepared. River sand and tap water from the city waterworks of Taipei (Taiwan) were used in this study. NWC and LWAC with compressive strength of $210 \mathrm{kgf} / \mathrm{cm}^{2}$ were used. Mix designs and variables considered are given in Table 1.

In practice, the dry (61) and wet (81) connectors are only subject to tensile force, whereas the bearing (56E) connector is subject to both tensile and shearing forces. Photographs of various steel connectors are displayed in Fig. 1.

Table 1. Concrete mixture parameter of specimens.

\begin{tabular}{llll}
\hline Items & & LWAC & NWAC \\
\hline Cement $\left(\mathrm{kg} / \mathrm{m}^{3}\right)$ & & 470 & 310 \\
Water $\left(\mathrm{kg} / \mathrm{m}^{3}\right)$ & & 220 & 204.56 \\
Coarse aggregate & $12.7 \mathrm{~mm}-9.52 \mathrm{~mm}$ & 148.46 & 486.04 \\
$\left(\mathrm{~kg} / \mathrm{m}^{3}\right)$ & $9.52 \mathrm{~mm}-4.76 \mathrm{~mm}$ & 186.31 & 484.19 \\
Sand $\left(\mathrm{kg} / \mathrm{m}^{3}\right)$ & & 713.17 & 797.93 \\
Air content $(\%)$ & & 2.5 & 2.5 \\
\hline
\end{tabular}




\subsection{Specimen preparation}

The three connectors were placed in LWAC and NWC wall specimens having the same compressive strength $(210 \mathrm{kgf} / \mathrm{cm} 2)$, and the mechanic behaviors and failure patterns of the specimens before and after firing were determined. Among them, dry-type (61) and wet-type (81) connectors are mostly used in the joint construction of "physical properties" and "construction requirements" in the construction of precast concrete, and the structures are less used for bearing weight. Therefore, only tension tests were performed in this study. The bearing-type (56E) steel connector is used in the connection function of "structural action," necessitating the conduct of two tests, tension and shearing.

The specimens were $30-\mathrm{m}$ thick and had dimensions of $1000 \times 1000 \times 150 \mathrm{~mm}^{3}(\mathrm{~L} \times \mathrm{W} \times \mathrm{H})$, as displayed in Fig. 2. The steel connector was placed between two pieces of wire mesh, and the reinforced steel was added around the hole. All sample numbers and experimental items are listed in Table 2.

\subsection{Configuration of steel connectors and steel walls}

The configuration of steel connectors within the wall specimens are displayed in Fig. 3. Wooden molds were used because of the number of wall specimens and workability requirements.

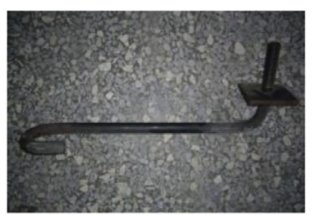

(a)

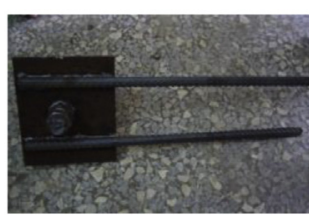

(b)

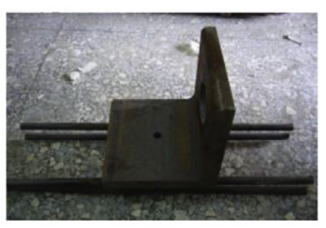

(d)

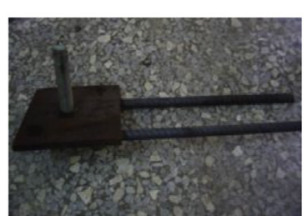

(c)

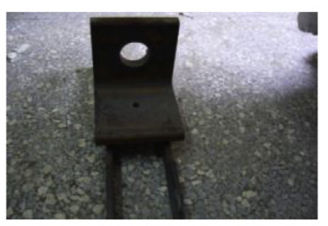

(e)
Fig. 1. Display of the steel connectors in this study (a) photo of the dry type (61) (b) top view's photo of the wet type (81) (c) side view's photo of the wet type (81) (d) top view's photo of the bearing type (56E) (e) side view's photo of the bearing type (56E).

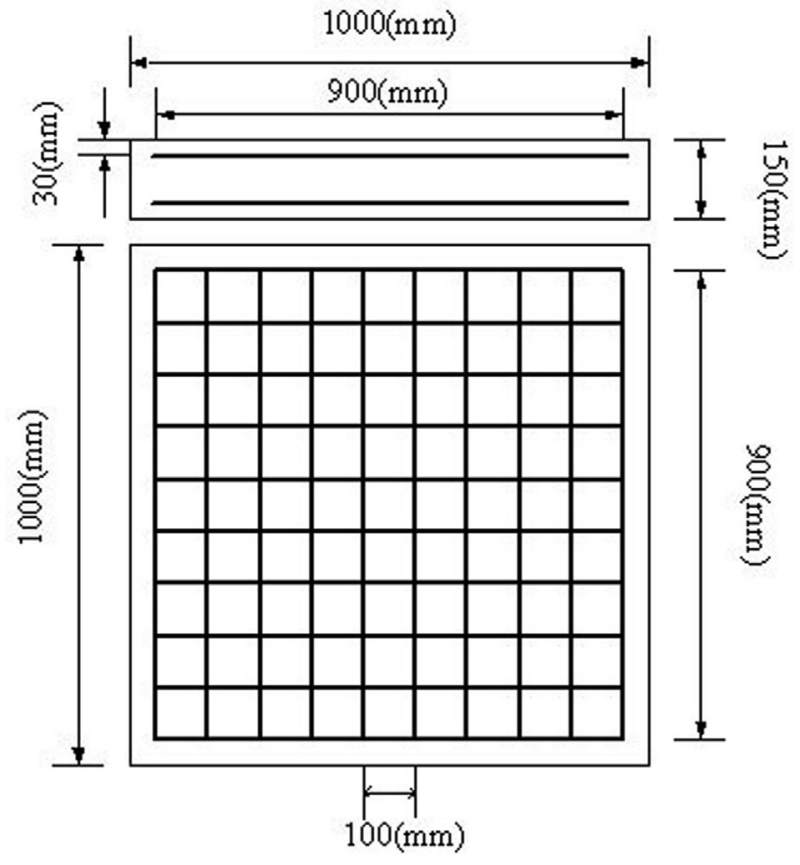

Fig. 2. Specimen size of the schematic diagram.

\subsection{Fire resistance test}

The aforementioned samples were placed in a high-temperature furnace and heated according to the ASTM E 119 standard. The samples were heated for $10 \mathrm{~min}$ to $700{ }^{\circ} \mathrm{C}$. The samples were then heated for $50 \mathrm{~min}$ to $950{ }^{\circ} \mathrm{C}$. To ensure that the temperature change in the high-temperature furnace conformed to the standard temperature rise curve, a thermal sensor (CH4 in Fig. 4) was placed on the outside of the wall. The measured temperature rise curve of

Table 2. Statistical sample numbers and experimental items.

\begin{tabular}{lllll}
\hline No & Series $^{\text {a }}$ & $\begin{array}{l}\text { Mechanic } \\
\text { behavior }\end{array}$ & $\begin{array}{l}\text { Fire resistance } \\
\text { test }\end{array}$ & $\begin{array}{l}\text { Type of } \\
\text { concrete }\end{array}$ \\
\hline 1 & NC(61)T1 & Tension test & $\times$ & NWAC \\
2 & NC(61)T2b & Tension test & $\bigcirc$ & NWAC \\
3 & LC(61)T1 & Tension test & $\times$ & LWAC \\
4 & LC(61)T2b & Tension test & $\bigcirc$ & LWAC \\
5 & NC(81)T1 & Tension test & $\times$ & NWAC \\
6 & NC(81)T2b & Tension test & $\bigcirc$ & NWAC \\
7 & LC(81)T1 & Tension test & $\times$ & LWAC \\
8 & LC(81)T2b & Tension test & $\bigcirc$ & LWAC \\
9 & NC(56E)T1 & Tension test & $\times$ & NWAC \\
10 & NC(56E)T2b & Tension test & $\bigcirc$ & NWAC \\
11 & LC(56E)T1 & Tension test & $\times$ & LWAC \\
12 & LC(56E)T2b & Tension test & $\bigcirc$ & LWAC \\
13 & NC(56E)V1 & Shearing test & $\times$ & NWAC \\
14 & NC(56E)V2b & Shearing test & $\bigcirc$ & NWAC \\
15 & LC(56E)V1 & Shearing test & $\times$ & LWAC \\
16 & LC(56E)V2b & Shearing test & $\bigcirc$ & LWAC \\
\hline X: & fire resistance &
\end{tabular}

$\mathrm{X}$ : No fire resistance test, O: Fire resistance test was conducted.

a (61): dry type (61); (81): wet type (81); (56E): bearing type (56E). 


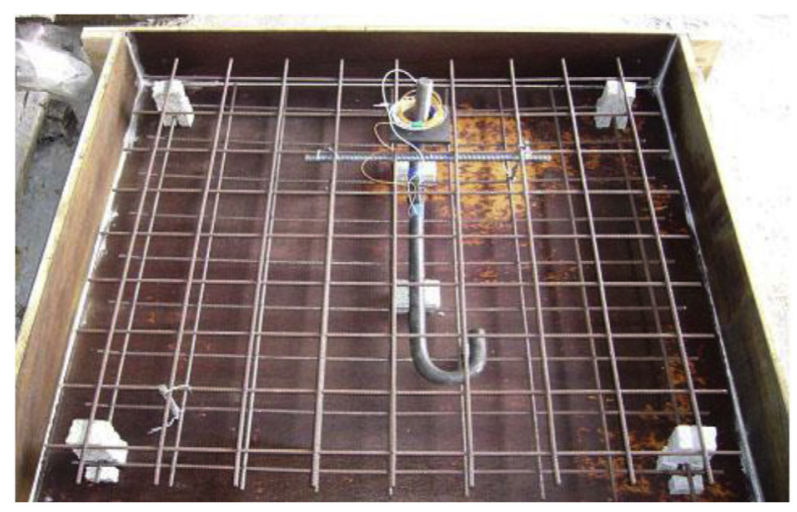

(a)

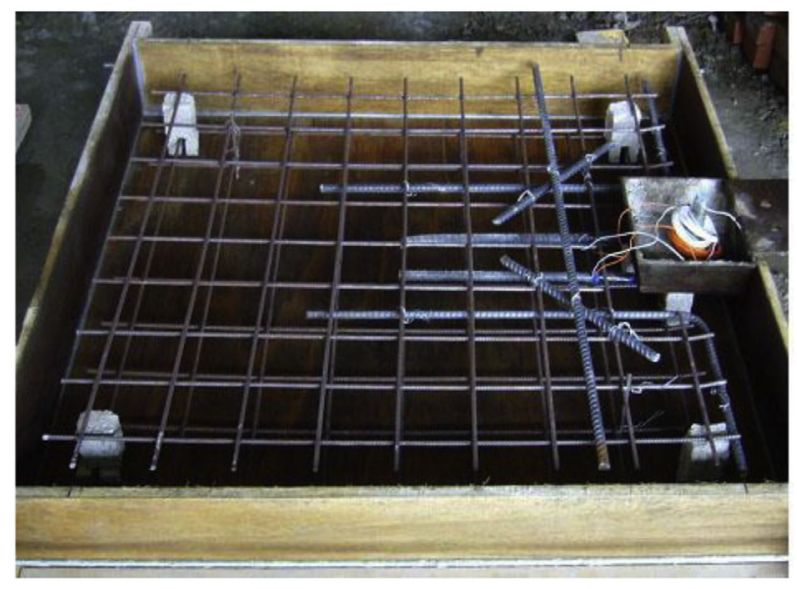

(b)

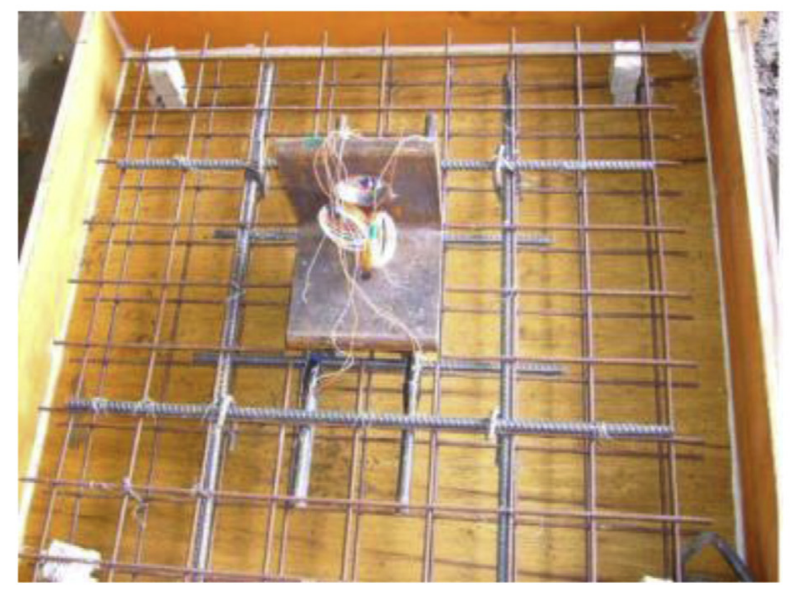

(c)

Fig. 3. Configuration of steel connectors within wall specimen (a) dry type (61) (b) wet type (81) (c) bearing type (56E). the high-temperature furnace matched the ASTM E119 curve (Fig. 5). Thermocouples ( $\mathrm{K}$ type, AZ8855) $\mathrm{CH} 1$ and $\mathrm{CH} 3$ and a thermal sensor $\mathrm{CH} 4$ were arranged as displayed in Fig. 4. The internal and external temperature changes in the wall under heating are displayed in Fig. 5. After the fire resistance test, the wall sample was removed from the furnace for further testing.

\subsection{Tension and shear tests}

First, the tension mold was installed on a 600-ton MTS universal testing machine, and the wall specimen was lifted at the test site using a stacker. The connector on the wall penetrated into the tension mold. A strong bolt was passed through the tension mold and the connector. The nut was then locked. The wall specimen was suspended on the aforementioned MTS universal testing machine by using the connector and tension mold. Then, the wall specimen was gently lowered to the rail; the four ends of the wall specimen of the fixed wall were used to lock the test specimen to the high-strength floor surface. After the strain gauges and other measuring devices were appropriately arranged, the tension test was performed, as illustrated in Fig. 6. The displacement control pulled the samples up at a rate of $0.03 \mathrm{~mm} / \mathrm{s}$. The measured data of the displacement and tension values were processed in the data collection system and analyzed.

For the shearing test of the wall specimen, the steel beam was first installed on the MTS universal testing machine. The vertical centerline of the measuring wall specimen was consistent with the center point of the steel girder; in the case of no

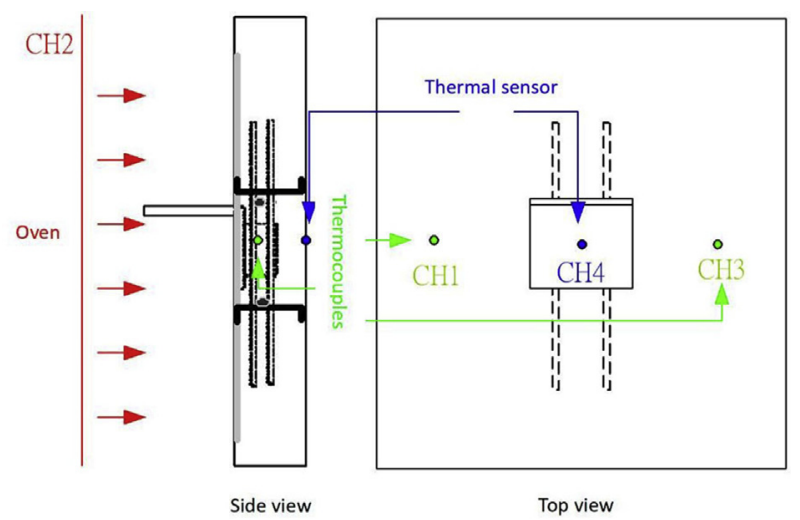

Fig. 4. The location of measuring point for specimens in the fire resistance test. 


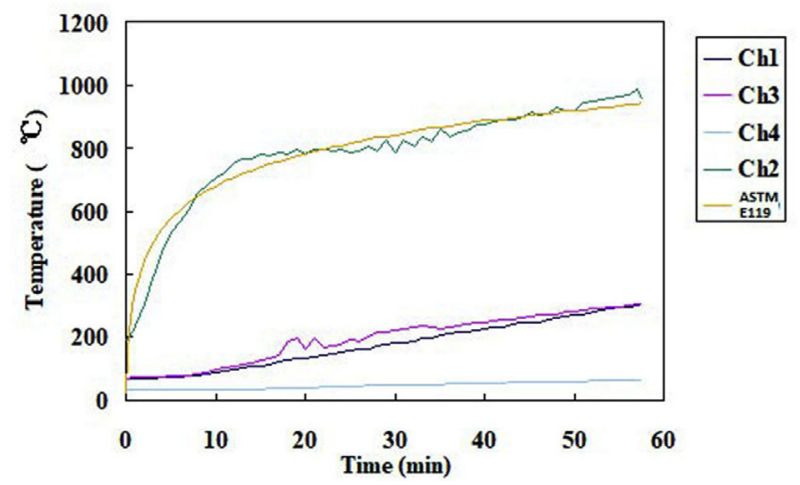

Fig. 5. The rising temperature curve of specimens in the fire resistance test.

eccentricity, the base was fixed using the groove steel seat and the bolt. A stacker was used to hang the wall specimens upright on the base, as displayed in Fig. 7, and the bolts were tightened. A strain

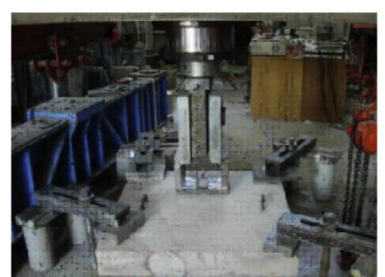

(a)

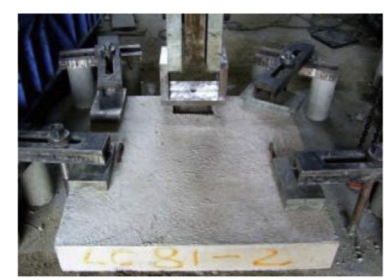

(b)

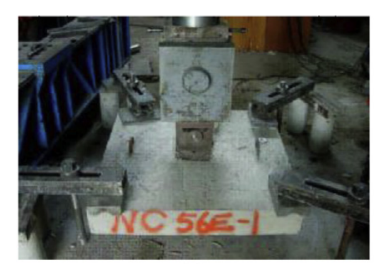

(c)

Fig. 6. Photos of tension test of wall specimens (a) dry type (61) (b) wet type (81) (c) bearing type (56E).

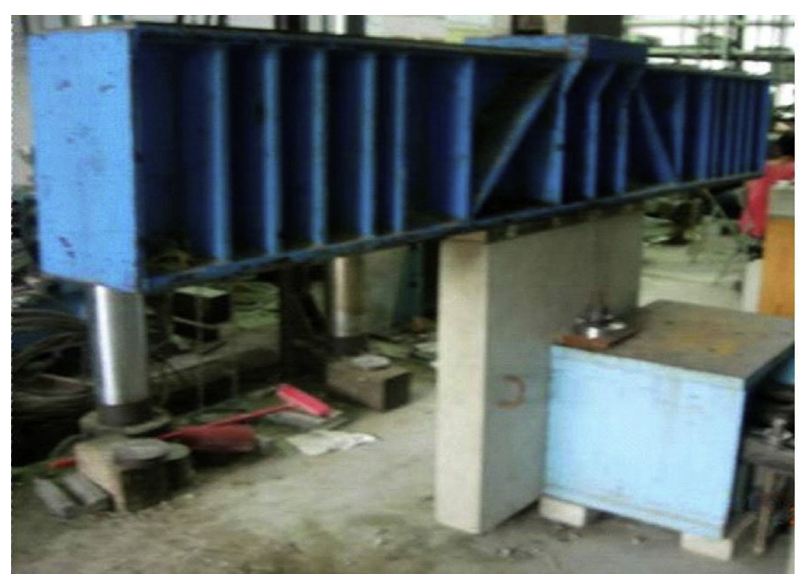

Fig. 7. Photo of shearing test of the bearing type (56E). gauge was attached to the appropriate surface of the wall specimens. Strain gauges were connected to the information collection system. In this experiment, a displacement control was used to reduce the pressure applied to the side of the wall specimens at a rate of $0.03 \mathrm{~mm} / \mathrm{s}$ so that the bearing connection produced an upward shear force. The displacement, shear force, and measured data were collected by the data collection system and then analyzed.

\section{Analysis and discussion of test results}

As presented in Table 1, dry, wet, and bearingtype connectors were used to prepare 16 lightweight and NWC wall specimens. Eight groups were first subjected to the fire resistance test and then the mechanical tests. The other eight groups were directly subjected to mechanical tests. The results of the experiments are analyzed in subsequent sections.

\subsection{Effect of the fire resistance test on the mechanical behaviors of the specimens}

\subsubsection{Dry connector}

As displayed in Table 3 , the cracking loads $\left(P_{\text {cr }}\right)$ of samples LC(61)T2b and LC(61)T1 were 2442 and $2569 \mathrm{kgf}$, respectively, and the ratio of their $P_{\mathrm{cr}}$ was $2442 / 2569=95.1 \%$; the ultimate loads $P$ u were 4847 and $5940 \mathrm{kgf}$, respectively, and the ratio of the ultimate load was $4847 / 5940=81.6 \%$. Similarly, the $P_{\mathrm{cr}}$ of specimens $\mathrm{NC}(61) \mathrm{T} 2 \mathrm{~b}$ and $\mathrm{NC}(61) \mathrm{T} 1$ were 2214 and $2808 \mathrm{kgf}$, respectively, and the ratio of the two cracking loads was $2214 / 2808=78.8 \%$. The $P u$ of the NC specimens was 3884 and $6023 \mathrm{kgf}$, respectively, and the ratio of the ultimate load was 3884/ $6023=64.5 \%$. The strength of the NWC wall specimens after the fire resistance test was considerably higher than that of the LWC wall specimens. The ultimate load decreased by $64.5 \%$. The fire resistance of the NWC wall was poor, whereas the fire resistance of the LWC wall was excellent. This result could be attributed to the manufacturing process. LWA is quenched at higher temperatures and has more pores. Limited loss of strength occurred in the LWA when subjected to a fire test because of its superior thermal stability, low thermal conductivity, and small thermal expansion coefficient. Although generally NWA has a good crystal structure, various rock components exhibit distinct expansion ratios $[34,35]$. Moreover, lower permeability may result in higher humidity in the heating process. The low porosity of the NWA caused the pore pressure to increase rapidly, which caused cracking and spalling of the wall, resulting in poor fire resistance. 
Table 3. Tension test results for wall specimens of the dry type (61).

\begin{tabular}{llllllll}
\hline Series & $\begin{array}{l}\text { Pcr } \\
(\mathrm{kgf})\end{array}$ & $\begin{array}{l}\mathrm{b} / \mathrm{a} \\
(\%)\end{array}$ & $\begin{array}{l}\text { Pu } \\
(\mathrm{kgf})\end{array}$ & $\begin{array}{l}\text { b/a } \\
(\%)\end{array}$ & $\begin{array}{l}\Delta \mathrm{u} \\
(\mathrm{mm})\end{array}$ & $\begin{array}{l}\Delta \text { max } \\
(\mathrm{mm})\end{array}$ & $\begin{array}{l}\text { Ductility } \\
\Delta \mathrm{max} / \Delta \mathrm{u}\end{array}$ \\
\hline (a)LC(61)T1 & 2569 & 95.1 & 5940 & 81.6 & 8.5 & 11.98 & 3.48 \\
(b)LC(61)T2b & 2442 & & 4847 & & 6.9 & 8.64 & 1.25 \\
(a)NC(61)T1 & 2808 & 78.8 & 6023 & 64.5 & 11.41 & 14.04 & 2.63 \\
(b)NC(61)T2b & 2214 & & 3884 & & 8.18 & 9.21 & 1.03 \\
\hline
\end{tabular}

Regarding ductility, the $\Delta \max / \Delta \mathrm{u}$ ratios of $\mathrm{LC}(61)$ $\mathrm{T} 2 \mathrm{~b}$ and LC(61)T1 were 1.25 and 3.48 , respectively (Table 3). Similarly, the $\Delta \max / \Delta \mathrm{u}$ ratio of $\mathrm{NC}(61) \mathrm{T} 2 \mathrm{~b}$ and NC(61)T1 were 1.03 and 2.63, respectively. After the fire resistance test, the difference in the ductility loss between the lightweight and NWC wall specimens was obvious because after LC(61)T2b and $\mathrm{NC}(61) \mathrm{T} 2 \mathrm{~b}$ were subjected to the fire test, the coefficient of elasticity of the concrete and the aggregate was reduced, which resulted in a decrease in the stiffness of the wall. After the fire test, the concrete samples gradually exhibited decomposition of cement hydrate and decay of pellets. Concrete spalling occurred on the surface of the specimen, which reduced the ductility of the specimen [23].

\subsubsection{Wet connector}

As presented in Table 4, the Pcr of LC(81)T2b and LC(81)T1 was 2187 and $2533 \mathrm{kgf}$, respectively, and the ratio of the cracked load was $2187 / 2533=86.3 \%$; $P \mathrm{u}$ was 4693 and $5176 \mathrm{kgf}$, respectively, and the ratio of the ultimate load was $4693 / 5176=90.7 \%$. The $P_{\text {cr }}$ of NC(81)T2b and NC(81)T1 was 1569 and $2456 \mathrm{kgf}$, respectively; the ratio of the cracked load was 1569 / $2456=63.9 \%$. The $P \mathbf{u}$ values of NC concrete specimens were 3781 and $5591 \mathrm{kgf}$, respectively. The ratio of the ultimate load was $3881 / 5591=67.6 \%$. Similarly, the high temperature of the fire test caused a greater reduction in the NWC wall than in the light wall; the cracked load decreased by as much as $63.9 \%$. Thus, the LWC wall exhibited excellent fire resistance.

In addition, the $\Delta \max / \Delta \mathrm{u}$ ratios of $\mathrm{LC}(81) \mathrm{T} 2 \mathrm{~b}$ and $\mathrm{LC}(81) \mathrm{T} 1$ were 1.29 and 1.61 , respectively, whereas the $\Delta \max / \Delta \mathrm{u}$ ratios of $\mathrm{NC}(61) \mathrm{T} 2 \mathrm{~b}$ and $\mathrm{NC}(61) \mathrm{T} 1$ were 1.1 and 1.29 , respectively. A similar phenomenon was observed for the ductility of the two specimens. The cause of ductility loss after the wall test specimens were subjected to the fire test is described in the previous section.

\subsubsection{Tension test}

As listed in Table 5 , the $P_{\text {cr }}$ of LC(56E)T2b and LC(56E)T1 was 4568 and $5501 \mathrm{kgf}$, respectively; the ratio of $P_{\mathrm{cr}}$ of the two specimens was $4568 /$ $5501=83.0 \%$; the $P u$ values of the two specimens were 9510 and 11,184 $\mathrm{kgf}$, respectively; the ratio of their ultimate loads was 9510/11,184 $=85.0 \%$. When subject to high temperature, the decrease of the two strengths was small, indicating that the light specimen has excellent fire resistance. Similarly, the cracking loads of NC(56E)T2b and NC(56E)T1 were 4233 and $5536 \mathrm{kgf}$, respectively; the ratio of the cracked load was $4233 / 5536=76.5 \%$; $P \mathrm{u}$ was 7310 and 11,642 kgf, respectively, and the ratio of the cracked load was $7310 / 11,642=62.8 \%$. A similar phenomenon was observed for the NWC

Table 4. Tension test results for wall specimens of the wet type (81).

\begin{tabular}{llllllll}
\hline Series & $\begin{array}{l}\text { Pcr } \\
(\mathrm{kgf})\end{array}$ & $\begin{array}{l}\mathrm{b} / \mathrm{a} \\
(\%)\end{array}$ & $\begin{array}{l}\text { Pu } \\
(\mathrm{kgf})\end{array}$ & $\begin{array}{l}\text { b/a } \\
(\%)\end{array}$ & $\begin{array}{l}\Delta \mathrm{u} \\
(\mathrm{mm})\end{array}$ & $\begin{array}{l}\Delta \text { max } \\
(\mathrm{mm})\end{array}$ & $\begin{array}{l}\text { Ductility } \\
\Delta \mathrm{max} / \Delta \mathbf{u}\end{array}$ \\
\hline (a)LC(81)T1 & 2533 & 86.3 & 5176 & 90.7 & 6.49 & 8.1 & 1.61 \\
(b)LC(81)T2b & 2187 & & 4693 & & 5.66 & 6.95 & 1.29 \\
(a)NC(81)T1 & 2456 & 63.9 & 5591 & 67.6 & 5.52 & 6.81 & 1.29 \\
(b)NC(81)T2b & 1569 & & 3781 & & 4.59 & 5.69 & 1.1 \\
\hline
\end{tabular}

Table 5. Tension test results for wall specimens of the bearing type (56E).

\begin{tabular}{llllllll}
\hline Series & $\begin{array}{l}\text { Pcr } \\
(\mathrm{kgf})\end{array}$ & $\begin{array}{l}\mathrm{b} / \mathrm{a} \\
(\%)\end{array}$ & $\begin{array}{l}\text { Pu } \\
(\mathrm{kgf})\end{array}$ & $\begin{array}{l}\mathrm{b} / \mathrm{a} \\
(\%)\end{array}$ & $\begin{array}{l}\Delta \mathrm{u} \\
(\mathrm{mm})\end{array}$ & $\begin{array}{l}\Delta \text { max } \\
(\mathrm{mm})\end{array}$ & $\begin{array}{l}\text { Ductility } \\
\Delta \mathrm{max} / \Delta \mathrm{u}\end{array}$ \\
\hline (a)LC(56E)T1 & 5501 & 83.0 & 11,184 & 85.0 & 9.12 & 14.09 & 4.97 \\
(b)LC(56E)T2b & 4568 & & 9510 & & 10.81 & 13.31 & 2.5 \\
(a)NC(56E)T1 & 5536 & 76.5 & 11,642 & 62.8 & 14.47 & 18.19 & 3.72 \\
(b)NC(56E)T2b & 4233 & & 7310 & & 8.85 & 11.73 & 2.88 \\
\hline
\end{tabular}




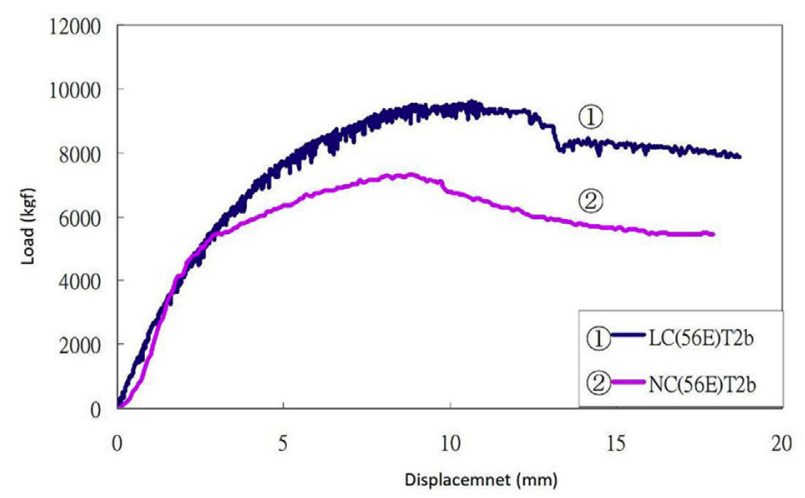

Fig. 8. The load-displacement $(P-\Delta)$ curve of the bearing type (56E) specimen for tension test after fire resistance test.

wall; the decrease in the extreme load was as high as $62.89 \%$.

Regarding ductility, as evident in Table 5 , the $\Delta \max / \Delta u$ ratios of $\mathrm{LC}(56 \mathrm{E}) \mathrm{T} 2 \mathrm{~b}$ and $\mathrm{LC}(56 \mathrm{E}) \mathrm{T} 1$ were 2.5 and 4.97, respectively. The $\Delta \max / \Delta \mathrm{u}$ ratios of NC(56E)T2b and NC(56E)T1 were 2.88 and 3.72, respectively. The ductility ratio losses of $\mathrm{NC}(56 \mathrm{E})$ $\mathrm{T} 2 \mathrm{~b}$ and $\mathrm{NC}(56 \mathrm{E}) \mathrm{T} 1$ were higher than those of the LWC wall. However, as displayed in Fig. 8, after the fire test, the load-displacement curve (the area covered by the load-displacement $[P-\Delta]$ curve [i.e., the hysteresis energy referred to in $[23,36]$ was considerably larger than that of the NWC wall. Under the same conditions, the absorbed hysteresis energy and seismic resistance of the LWC wall were still higher than the NWC wall.

\subsubsection{Shear test}

As presented in Table 6 , the $P_{\text {cr }}$ of LC(56E)V2b and LC(56E)V1 were 45,044 and 51,067 kgf, respectively; the ratio of their $P_{\mathrm{cr}}$ values was $45,044 /$ $51,067=88.2 \%$. The $P_{\text {cr }}$ of NC(56E)V2b and NC(56E) V1 were 41,217 and 51,229 kgf, respectively; the ratio of their cracked loads was $41,217 / 51,229=80.6 \%$. The effect of the high temperature of the fire test on the NWC wall was greater than that on the LWC wall, but the difference was not large. Furthermore, the results of the shearing test revealed that irrespective of the wall, once the specimen cracked, then the structure was destroyed immediately;

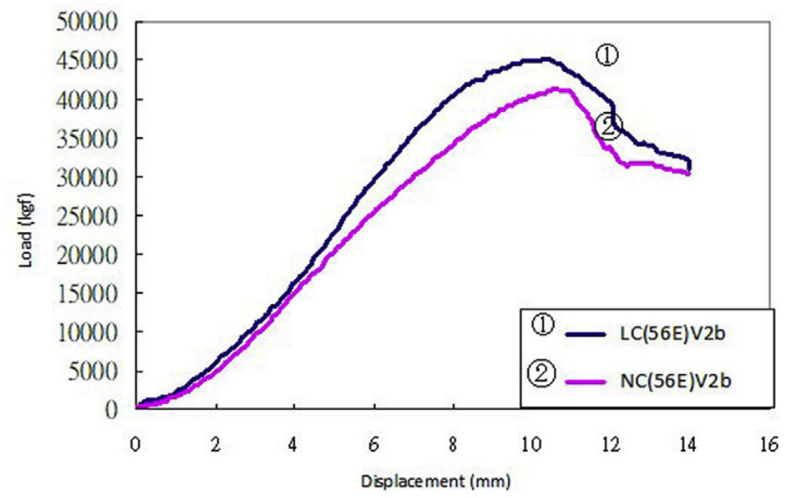

a

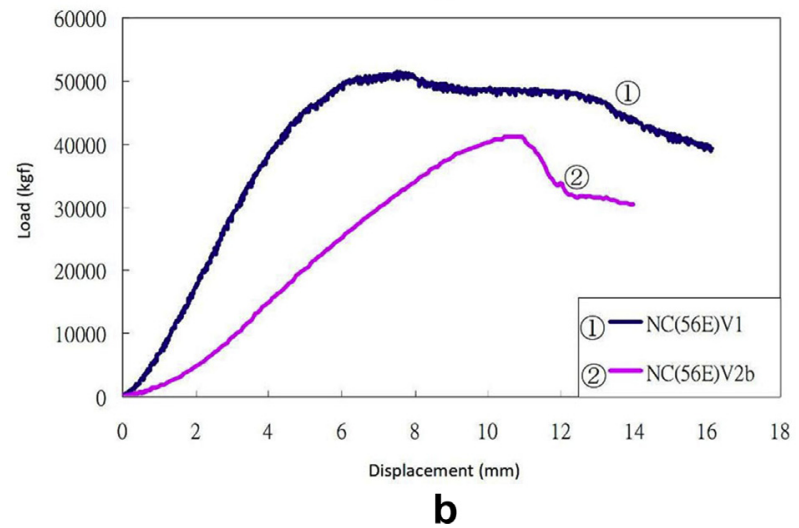

Fig. 9. The load-displacement (P- $\Delta$ ) curve of the bearing type (56E) specimen for shearing test (a) lightweight and normal weight wall after the fire resistance test (b) before and after the fire resistance test for normal weight wall.

therefore, the $P \mathrm{cr}$ and $\mathrm{Pu}$ values were close. The $\Delta \max / \Delta u$ ratios of $\mathrm{LC}(56 \mathrm{E}) \mathrm{V} 2 \mathrm{~b}$ and $\mathrm{LC}(56 \mathrm{E}) \mathrm{V} 1$ were 1.37 and 1.17 , respectively. The $\Delta \max / \Delta \mathrm{u}$ ratios of NC (56E)V2b and NC(56E)V1 were 1.64 and 1.10, respectively. After the fire resistance test, the difference in ductility between the LWC wall and the NWC wall was not large.

As presented in Table 6 , the $\Delta \max / \Delta \mathbf{u}$ ratios of LC(56E)V2b and NC(56E)V2b were 1.17 and 1.10, respectively. As displayed in Fig. 9(a), the area covered by the load-displacement curve of LC(56E) $\mathrm{V} 2 \mathrm{~b}$ (i.e., the hysteresis energy), was still larger than that of NC(56E)V2b. Under the same conditions, the hysteresis energy that can be absorbed and the

Table 6. Comparison of shearing test results for wall specimens of the bearing type (56E).

\begin{tabular}{llllll}
\hline Series & $\begin{array}{l}\text { Pcr } \\
(\mathrm{kgf})\end{array}$ & $\begin{array}{l}\mathrm{b} / \mathrm{a} \\
(\%)\end{array}$ & $\begin{array}{l}\Delta \mathrm{u} \\
(\mathrm{mm})\end{array}$ & $\begin{array}{l}\Delta \max \\
(\mathrm{mm})\end{array}$ & $\begin{array}{l}\text { Ductility } \\
\Delta \mathrm{max} / \Delta \mathbf{u}\end{array}$ \\
\hline (a)LC(56E)V1 & 51,067 & 88.2 & 11.32 & 15.56 & 1.37 \\
(b)LC(56E)V2b & 45,044 & & 10.34 & 12.06 & 1.17 \\
(a)NC(56E)V1 & 51,229 & 80.6 & 7.84 & 12.86 & 1.64 \\
(b)NC(56E)V2b & 41,271 & & 10.61 & 11.69 & 1.10 \\
\hline
\end{tabular}


seismic resistance of the LWC wall were still higher than those of the NWC wall. Fig. 9(b) displays that the NC(56E)V2b and NC(56E)V1 specimens exhibited a large difference in the area covered by the two load-displacement curves before and after the tests. Thus, the NWC walls exhibited a large decrease in hysteresis energy and seismic resistance.

\subsection{Effect of the fire resistance test on the failure patterns of specimens}

\subsubsection{Dry connector}

The crack growth condition, shape, position, direction, and specimen failure of LC(61)T2b and $\mathrm{NC}(61) \mathrm{T} 2 \mathrm{~b}$ were similar. When the tensile force was lower than the cracked load, the tensile force and joint displacement maintained a linear relationship. As the tensile force approached the cracked load, cracks began to form on the concrete surface around the connector, as displayed in Fig. 10(b). The cracks gradually extended, the width of the cracks increased, and the concrete protective layer on the wall surface began to collapse. The concrete function was gradually lost. Most of the tensile force was transferred to the joint of the iron and steel inside the wall until the sample was destroyed, as presented in Fig. 10(a). The cracks and damage related to the specimen are displayed in Fig. 10.

\subsubsection{Wet connector}

The LC(81)T2b connector did not have any reinforcement mesh or concrete protection layer; when the tensile force was lower than the cracked load, the tension and displacement maintained a linear relationship. As the tension increased to the cracked load, the concrete underneath the steel connector began to crack. When the tension load equaled the cracked load, the connector was pulled, and the turning trend of the strain increased. As the experiment progressed, the cracks gradually extended, the width of the cracks increased, and the concrete protective layer on the surface of the specimen

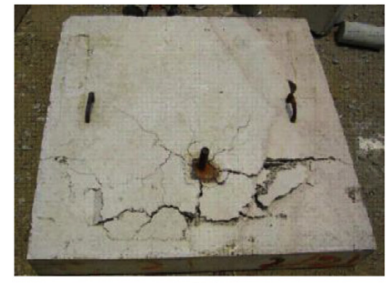

(a)

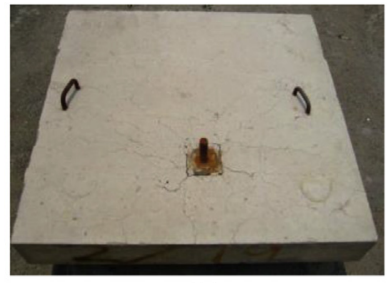

(b)

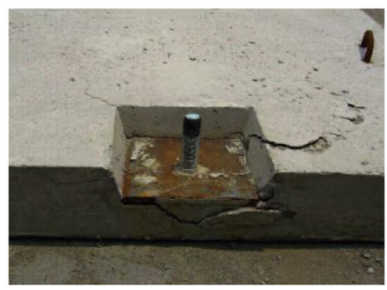

(a)

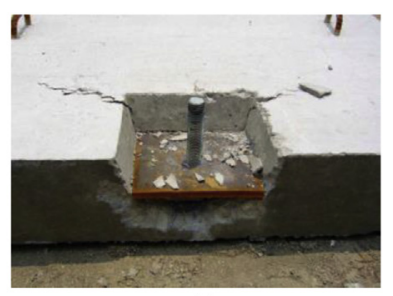

(b)
Fig. 11. The failure patterns of the wet type (81) specimen for tension test after the fire resistance test (a) specimen LC(81)T2b (b) specimen NC(81)T2b.

began to collapse, as displayed in Fig. 11(a). The tensile force was mostly concentrated on the steel connector until the structure was destroyed.

The phenomena of crack growth, shape, position, direction, and destruction of $\mathrm{NC}(81) \mathrm{T} 2 \mathrm{~b}$ were similar to those of LC(81)T2b, but the cracked load and ultimate load were both lower than those of $\mathrm{LC}(81) \mathrm{T} 2 \mathrm{~b}$. When the wall was subjected to a tension test, the first obvious crack occurred in the concrete at the bottom of the connector. In addition to the tensile force at the connector, a bending moment occurred at the connector between the connector and the concrete. The final failure pattern was a reverse cone below the connector, as displayed in Fig. 11(b). In addition to the upward displacement caused by the vertical tension at the connector, a slight angle of inclination due to the bending moment also occurred. The cracks and damage of the wall specimens are displayed in Fig. 11.

\subsubsection{Bearing tension test}

After the fire resistance test, when the tensile force was lower than the cracked load, the tension and the connector displacement maintained a linear relationship. As the tension increased to the cracked load, the concrete protective layer around the connector began to crack. When the connector was subjected to tension, the strain in front of the

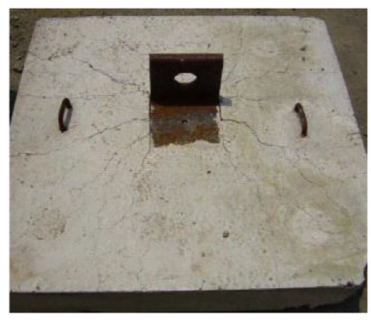

(a)

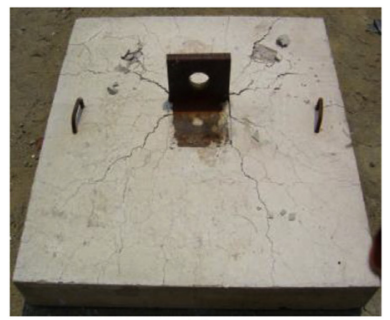

(b)
Fig. 10. The failure patterns of the dry type (61) specimen for tension test after the fire resistance test (a) specimen LC(61)T2b (b) specimen NC(61)T2b.
Fig. 12. The failure patterns of the bearing type (56E) specimen for tension test after the fire resistance test (a) specimen LC(56E)T2b (b) specimen NC(56E)T2b. 
connector differed from that in the rear reinforcement. As the experiment progressed, the cracks gradually extended; the width of the cracks increased and extended to the periphery, as displayed in Fig. 12(a). The concrete surface of the specimen surface began to collapse, and most tensile force was transferred to the steel connectors until the specimen was destroyed, as displayed in Fig. 12(b).

When LC56E)T2b and NC(56E)T2b were subjected to tension tests, the failure patterns of the two specimens were similar. In addition to the upward vertical tension force, the connectors produced a bending moment. The reinforcement on the back of the connector could withstand the upward vertical tension and bending moment. Therefore, the concrete on the back of the connector caused serious damage and breakout. In Fig. 12(b), the damage on the back of the connector was severe. By contrast, only concrete cracks were generated on the front concrete of the connector and no obvious failure patterns were observed, as displayed in Fig. 12(a). The cracks and damage of wall specimens are displayed in Fig. 12.

\subsubsection{Shearing test}

When the shearing test was performed on LC56E) $\mathrm{V} 2 \mathrm{~b}$ and $\mathrm{NC}(56 \mathrm{E}) \mathrm{V} 2 \mathrm{~b}$, the failure patterns of the two specimens were similar. As illustrated in Fig. 7, the center of the wall and the base were not in the same line. Due to the eccentric action, when the wall moved downward, the reaction force of the base generated an eccentric bending moment to the connector. The aforementioned bending moment exerted pressure on the concrete above the steel connector and generated a tensile force below. Furthermore, when the wall moved downward, the wall and connector interface produced an upward shear force, which in turn caused a shear force on the concrete above the connector. This shear force caused a pull force on the lower side. In summary, the concrete above the connector was subjected to pressure and shear force simultaneously; its failure patterns are displayed in

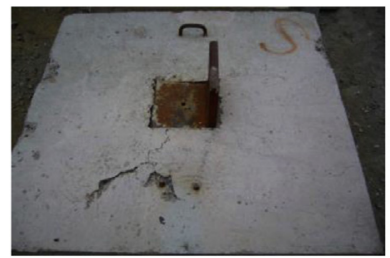

(a)

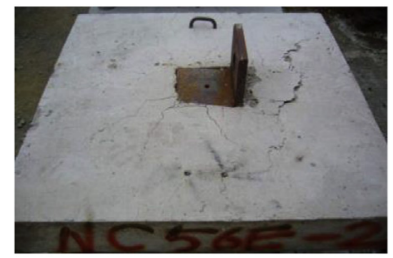

(b)
Fig. 13. The failure patterns of the bearing type (56E) specimen for shearing test after the fire resistance test (a) specimen LC(56E)V2b (b) specimen NC(56E)V2b.
Fig. 13(b). Conversely, the concrete under the connector was subjected to two-way tensile forces simultaneously. The failure patterns are displayed in Fig. 13(a). As displayed in Fig. 13, the cracks produced in the NWC wall were more pronounced than those in the LWC wall; after the specimen was destroyed, the steel connectors were slightly inclined because of the bending moment.

\subsection{Summary}

The results indicate that the three connectors are suitable for precast LWC walls and NWC walls. The ductility, tension, and shearing test results of lightweight and NWC walls were similar, and they exhibited similar mechanic behaviors and failure patterns. No two-stage failure occurred during the shearing test of lightweight and NWC walls. However, the mechanic behavior and seismic resistance of the LWC walls were superior to those of NWC walls because the LWC inside the wall specimen was produced under high heat. Therefore, the effect of the high temperature on LWC was not as severe. By contrast, NWC concrete is not manufactured under high temperature. When subjected to fire and high temperature, the internal material properties of the aggregate are partially destroyed, resulting in the reduction of the $E$ value (coefficient of elasticity) of the normal weight aggregate and concrete.

\section{Conclusions}

This study evaluated three connectors commonly used in precast engineering and determined the differences in mechanic behaviors and failure patterns of lightweight and NWC wall specimens before and after the fire resistance test. Furthermore, the effect of three steel connectors on fire resistance was investigated. According to the results of the tests, the three steel connectors used for the fire resistance of the LWC wall enabled it to exhibit superior resistance to the NWC wall. Thus, the LWC wall retained its excellent structural performance after being heated at a high temperature of the standard heating curve.

The study revealed that in the tension test after the fire resistance test, the lightweight and NWC walls exhibited similar mechanic behaviors and failure patterns. For the LWC wall specimen with the dry connector, the cracked and ultimate loads decreased to $95.1 \%$ and $81.6 \%$ of the original load, respectively, after the fire test. For the NWC wall with the dry connector, the cracked and ultimate loads decreased to $78.8 \%$ and $64.5 \%$ of the original load, respectively. The LWC wall exhibited fire resistance superior to 
that of the NWC wall. For the wet connector, the cracked and ultimate loads decreased to $86.3 \%$ and $90.7 \%$ of the original load, respectively. For the NWC wall specimen with the wet connector, the cracked and ultimate loads decreased to $63.9 \%$ and $67.6 \%$ of the original load, respectively. The LWC wall exhibited superior fire resistance to that of the NWC wall. For the bearing-type connector, the cracked and ultimate loads were $83.0 \%$ and $85.0 \%$ of the original loads, respectively. The cracked and ultimate loads of the bearing-type NWC wall specimens decreased to $76.5 \%$ and $62.8 \%$ of the original loads, respectively. Although the loss ratio of the NWC wall was higher than that of the LWC wall after the fire resistance test, the hysteresis energy that was absorbed and the seismic resistance of the LWC wall were still higher than those of the NWC wall.

The experiment results revealed that in the shearing test after the fire resistance test, the cracked load of the LWC specimen of the bearing type decreased to $88.2 \%$ of the original load. For the NWC wall specimen, the cracked load of the bearing type decreased to $80.6 \%$ of the original load. Furthermore, the ductility loss of LWC and NWC wall specimens was considerable. However, the hysteresis energy that was absorbed and the seismic resistance of the LWC wall were still higher than those of the NWC wall.

Furthermore, the failure patterns of the bearingtype connector in the LWC and NWC walls were the same. Two-stage failure patterns of cracking and ultimate load did not occur and the specimens were damaged instantly once broken. Dry and wet connectors were subjected to tension, and the bearingtype connector was subjected to shearing. The cracking behavior of the wall specimens basically reflected the tension and shearing behaviors of concrete before a crack occurred in the specimens. When the tensile force was subjected to the bearingtype connector, except for the steel connector, it was based on the tension behavior of reinforced mesh and reinforced steel inside the wall specimen.

\section{Conflict of interest statement}

The authors declared that they have no conflicts of interest to this work. We declare that we do not have any commercial or associative interest that represents a conflict of interest in connection with the work submitted.

\section{Acknowledgments}

During the research time, the research team received a kind subsidiary budget from the Ministry of Science and Technology (project number: NSC 952221-E-005-126-MY3). Besides, the colleagues from Dr. Jun-Ren Tang, Mr. Kai-Shun You also providing precious information and experimental assistant. We would like to express our sincerely gratitude.

\section{References}

[1] Moceikis R, Kičaitè A. Aar in precast concrete wall elements. Proc Eng 2017;195:244-51.

[2] Kim MO, Justnes H, Qian X. Application of structural lightweight aggregate concrete in floating marine concrete structures - a review. In: Paper presented at the The Twenty-Ninth KKHTCNN Symposium on Civil Engineering, Hong Kong, China; 2016, December 3-5.

[3] Wernli M, Easley R, Springston PS. New technologies proven in precast concrete modular floating pier for U.S. Navy. PCI J 2005:76-99.

[4] Lee D-E, Kim Y, Kim S. Development and application of precast concrete double wall system to improve productivity of retaining wall construction. Sustainability 2020;12(8):3454. https://doi.org/10.3390/su12083454.

[5] Arioz O. Effects of elevated temperatures on properties of concrete. Fire Saf J 2007;42:516-22.

[6] Gwynne SMV, Kuligowski ED, Kinsey MJ, Hulse LM. Modelling and influencing human behaviour in fire. Fire Mater 2017;41(5):412-30.

[7] Husem M. The effects of high temperature on compressive and flexural strengths of ordinary and high-performance concrete. Fire Saf J 2006;41:155-63.

[8] Sekizawa A, Mizuno M. Analysis of response behavior of people in fire incidents where residential fire alarms successfully worked. Fire Mater 2017;41(5):441-53.

[9] Gales J, Bisby LA, Gillie M. Unbonded post tensioned concrete in fire: a review of data from furnace tests and real fires. Fire Saf J 2011;46:151-63.

[10] Jau WC, Huang KL. A study of reinforced concrete corner columns after fire. Cement Concr Compos 2008;30:622-38.

[11] Kodura VKR, Phanb L. Critical factors governing the fire performance of high strength concrete systems. Fire Saf J 2007;42:482-8.

[12] Ma CK, Awang AZ, Omar W. Structural and material performance of geopolymer concrete: a review. Construct Build Mater 2018;186:90-102.

[13] Bogas JA, Carriço A, Ontes J. Influence of cracking on the capillary absorption and carbonation of structural lightweight aggregate concrete. Cement Concr Compos 2019;104. https://doi.org/10.1016/j.cemconcomp.2019.103382.

[14] Demirdag S, Gunduz L. Strength properties of volcanic slag aggregate lightweight concrete for high performance masonry units. Construct Build Mater 2008;22:135-42.

[15] Dixit A, Pang SD, Kang SH, Moon J. Lightweight structural cement composites with expanded polystyrene (EPS) for enhanced thermal insulation. Cement Concr Compos 2019; 102:185-97.

[16] Greifenhagen C, Lestuzzi P. Static cyclic tests on lightly reinforced concrete shear walls. Eng Struct 2005;27:1703-12.

[17] Hossain KMA. Properties of volcanic pumice based cement and lightweight concrete. Cement Concr Res 2004;34:283-91.

[18] Kockal NU, Ozturan T. Durability of lightweight concretes with lightweight fly ash aggregates. Construct Build Mater 2011;25:1430-8.

[19] Pilehvar S, Cao VD, Szczotok AM, Carmona M, Valentini L, Lanzón M, et al. Physical and mechanical properties of fly ash and slag geopolymer concrete containing different types of micro-encapsulated phase change materials. Construct Build Mater 2018;173:28-39.

[20] Waldmann D, May A, Thapa VB. Influence of the sheet profile design on the composite action of slabs made of 
lightweight woodchip concrete. Construct Build Mater 2017b;148:887-99.

[21] Zhou Y, Xi B, Sui L, Zheng S, Xing F, Li L. Development of high strain-hardening lightweight engineered cementitious composites: design and performance. Cement Concr Compos 2019;104. https://doi.org/10.1016/j.cemconcomp.2019.103370.

[22] Go CG, Thang JR, Chi JH, Chen CT, Huang YL. Fire-resistance property of reinforced lightweight aggregate concrete wall. Construct Build Mater 2012;30:725-33.

[23] Chi JH, Thang JR, Go CG, Huang YL. Research on seismic resistance and mechanic behavior of reinforced lightweight Aggregate concrete walls after high temperature. Fire Mater 2014;38:789-805.

[24] Coppola L, Coffetti D, Crotti E, Marini A, Passoni C, Pastore T. Lightweight cement-free alkali-activated slag plaster for the structural retrofit and energy upgrading of poor quality masonry wall. Cement Concr Compos 2019;104. https://doi.org/10.1016/j.cemconcomp.2019.103341.

[25] Robinson GP. Design and performance of precast concrete structures. Leicestershire: United Kingdom: Loughborough University; 2014 (Ph.D).

[26] Alengaram UJ, Muhit BAA, Jumaat MZB. Utilization of oil palm kernel shell as lightweight aggregate in concrete - a review. Construct Build Mater 2013;38:161-72.

[27] Alghamri R, Kanellopoulos A, Al-Tabbaa A. Impregnation and encapsulation of lightweight aggregates for self-healing concrete. Construct Build Mater 2016;124:910-21.

[28] Colangelo F, Roviello G, Ricciotti L, Ferrándiz-Mas V, Messina F, Ferone $C$, et al. Mechanical and thermal properties of lightweight geopolymer composites. Cement Concr Compos 2018;86:266-72.

[29] Ibrahim GS, Yousry BS, Essam LE, Osama AK, Peter AA. Flexural characteristics of lightweight ferrocement beams with various types of core materials and mesh reinforcement. Construct Build Mater 2018;171:802-16.

[30] Waldmann D, May A, Thapa VB. Influence of the sheet profile design on the composite action of slabs made of lightweight woodchip concrete. Construct Build Mater 2017a; 148:887-99.

[31] Bardhan-Roy BK. Lightweight aggregate concrete in UK. In: Paper presented at the International Symposium on Structural Lightweight Aggregate Concrete, Norway; June, 1995.

[32] Helgesen $\mathrm{KH}$, June. Lightweight aggregate concrete in Norway. In: Paper presented at the International Symposium on Structural Lightweight Aggregate Concrete, Norway; 1995.

[33] ASTM C 150. Standard specification for Portland cement. American Society for Testing Materials; 2017.

[34] Chi M. Mechanical strength and durability of alkaliactivated fly ash/slag concrete. J Mar Sci Technol 2016;24(5): 958-67.

[35] Chi M, Huang R. Effect of circulating fluidized bed combustion ash on the properties of roller compacted concrete. Cement Concr Compos 2014;45:148-56.

[36] Li Y, Xu M. Hysteresis loop and energy dissipation of viscoelastic solid models. Mech Time-Dependent Mater 2007;11(1):1-14. 